with conventional cuprophane membranes. ${ }^{4}$ Haemodialysis with high flux dialysers and polysulfone or polyacrylonitrile membranes lowers $\beta_{2}$ microglobulin concentrations, and an improvement in shoulder pain in patients changed to high flux dialysers has been reported. ${ }^{5}$ The mechanism of the improvement is not clear; possibly amyloid is no longer deposited and the associated inflammation decreases. The improved biocompatibility of these membranes is known to be associated with reduced activation of some mediators of the inflammatory response.

Our patient used polysulfone dialysers after his operation, and his initial improvement was maintained. Monitoring the amyloid deposits throughout his spinal canal should show the effect of high flux dialysis on further deposition of amyloid.

We thank Dr M Owen, who performed the myelography; Dr D Sethi for advice; and Dr J M Rice-Edwards, who performed the laminectomy.

1 Prasad BK, Andrews K, Dutton J, Reid H. Localised amyloid deposit producing paraplegia Br Med J 1981;283:1087.

McAnena OJ, Feely MP, Kealy WF. Spinal cord compression by amyloid tissue. $\mathcal{f}$ Neurol Neurosurg Psychiatry 1982:45:1067-9.

3 Cary NRB, Sethi D, Brown EA, Erhardt CC, Woodrow DF, Gower PE. Dialysis arthropathy: amyloid or iron? Br Med f 1986;293:1392-4.

4 Vincent $C$, Revillard JP, Galland $M$, Traeger J. Serum $\beta_{2}$-microglobulin in haemodialyzed patients. Nephron 1978;21:260-8.

5 Ackrill P, Robinson EL, Chattopadhyay C, Hill K, McClure JC. Removal of $\beta_{2}$-microglobulin in patients on long term haemodialysis. Life Support Systems Abstracts 1986;4(suppl):1.

(Accepted 18 November 1987)

Departments of Medicine and Histopathology, Charing Cross Hospital, London W6 8RF

T J ALLAIN, BSC, MB, senior house officer

P E STEVENS, BSC, MRCP, senior registrar

L R BRIDGES, BSC, $M B$, lecturer in neuropathology

M E PHILLIPS, MD, FRCP, consultant nephrologist

Correspondence to: Dr Allain.

\section{Strongyloidiasis in ex-Far East prisoners of war}

Altogether 38000 men who had been prisoners of war in the Far East returned to Britain after the second world war. There has recently been growing concern that some of those surviving might still be harbouring the tropical worm Strongyloides stercoralis. In 1982 the Department of Health and Social Security agreed to mount a nationwide screening programme and recruited 11 hospitals, seven of them military. The programme was named the tropical disease investigation and was organised by the department's War Pensions Branch, which assigned these former prisoners of war to the hospitals nearest to their homes. I report on the first 500 patients screened at this hospital.

\section{Patients, methods, and results}

From April 1982 up to four patients a week were admitted to this hospital for five days of investigations. Their ages ranged from 59 to 81 . All patients underwent routine screening for tropical diseases and had a full medical and psychiatric examination with appropriate investigations. Some further tests were aimed specifically at strongyloidiasis: these consisted of a differential white cell count, stool tests, and a string test (Entero test).

Strongyloidiasis was identified in 78 of the first 500 subjects tested. Seventy three had a convincing history of classical larva currens rash, and five were asymptomatic but positive for larvas on stool testing. All 78 were treated with thiabendazole $25 \mathrm{mg} / \mathrm{kg}$ twice daily for three days. Three patients with a history of rash did not complete the treatment. A minimum of 12 months later we wrote to the 70 patients with symptoms. Of the 64 who replied, 38 claimed to be cured. Because of the unpleasant side effects of thiabendazole only 15 of the remaining 26 agreed to further treatment. Four were considered to be cured 12 months after their second course of thiabendazole. Four of the five asymptomatic patients were reviewed in hospital one to three years after treatment. Three were found to be negative for the larva on stool testing and had normal eosinophil counts; they were judged to be cured. Thus 45 of the 68 patients $(66 \%)$ reviewed 12 months or more after the initial treatment were found to be free of infection.

\section{Comment}

Patients with chronic strongyloidiasis often have few symptoms other than mild looseness of the bowels. The larva currens rash, an intensely irritating recurrent urticarial eruption, is usually unmistakable and is diagnostic, especially when accompanied by eosinophilia. In most long established cases this rash tends to recur at long intervals. In many patients it may be little more than an inconvenience.

The chief danger to life is the hyperinfection syndrome, in which the immune defences are overwhelmed and there may be massive dissemination of larvas from the general circulation to vital organs, possibly with a fatal outcome. ${ }^{2}$ The syndrome may be provoked by certain malignancies and chronic debilitating diseases, including the acquired immune deficiency syndrome. ${ }^{3}$ Immunosuppressant drugs such as high dose steroids are an important cause of the hyperinfection syndrome.

Our cure rate was $66 \%$; as thiabendazole produces unpleasant side effects a less toxic and more effective drug is needed. ${ }^{4}$ This hospital now offers a second course of treatment a month after the first.

Strongyloidiasis may run a mild or asymptomatic course: five patients positive for larvas on stool testing had no symptoms. Thirteen patients who did not receive treatment had unexplained eosinophilia. Thus the prevalence of infection reported here $(16 \%)$ may be an underestimate; $20 \%$, as suggested by Gill and Bell, may be more realistic. ${ }^{5}$ As strongyloidiasis may be becoming more common in Britain doctors intending to treat their patients with immunosuppressant drugs should ask whether they were prisoners of war in the Far East or have lived in the tropics. Unexpected reactions to treatment with immunosuppressants could necessitate a life saving course of treatment.

The 11 hospitals taking part in the Tropical Disease Investigation are the Royal Liverpool Hospital; London School of Tropical Medicine; City Hospital, Edinburgh; Coppetts Wood Hospital, London; Royal Naval Hospital Haslar, Gosport; Royal Naval Hospital, Plymouth; Queen Elizabeth Military Hospital, Woolwich, London; Princess of Wales Royal Air Force Hospital, Ely; Princess Mary's Royal Air Force Hospital, Halton, Aylesbury; Princess Alexandra Hospital, Wroughton, Swindon; and Royal Air Force Hospital, Nocton Hall, Lincolnshire.

1 Wong B. Parasitic diseases in immunocompromised hosts. Am J Med 1984;76:479-85. 2 Purtilo DT, Meyers WM, Connor DH. Fatal strongyloidiasis in immunosuppressed patients. Am f Med 1974;56:488-93.

3 Pialoux G, Beniel P, Caudron J, Chousterman M, Meyrignac C. Syndrome d'immunodépression acquise associé à une augiallose sévère. Presse Médicale 1984;13:1960

4 Grove DI. Treatment of strongyloidiasis with thiabendazole: an analysis of toxicity and effectiveness. Trans $R$ Soc Trop Med Hyg 1982;76:114-8.

5 Gill GV, Bell DR. Strongyloides stercoralis infection in former Far East prisoners of war. Br Med f 1979;ii:572-4

(Accepted 16 November 1987)

Princess of Wales Royal Air Force Hospital, Ely, Cambridgeshire CB6 1DN J A HILL, MB, FRCP, consultant physician

\section{Laparoscopic incisions at the lower umbilical verge}

When punctured with a cone skin splits along the direction of its collagen bundles; the topographical alignment of these fibres is commonly referred to as Langer's lines. ${ }^{1}$ Incisions along these lines are believed to heal with less formation of keloid than incisions crossing the lines. ${ }^{23}$ If Langer's lines run vertically at the lower umbilical verge vertical incisions here should be cosmetically superior to horizontal incisions. We carried out a study to test this.

\section{Patients, methods and results}

The study was in two parts, the first being to determine which incisional axis, horizontal or vertical, would produce the best cosmetic result and the second to determine the direction of Langer's lines at the lower umbilical verge. We obtained the approval of the local ethical committee and the participating patients' informed consent for the study.

Twenty women undergoing laparoscopy for the first time were allocated alternately to receive a vertical or horizontal incision. A number 11 scalpel blade and a $7 \mathrm{~mm}$ operating laparoscope were used; incisions were closed with a single 2-0 plain catgut subcuticular horizontal mattress suture. Eighteen women were available for review three months later and used a $10 \mathrm{~cm}$ visual analogue scale to assess the cosmetic result of their scars. The women with vertical scars graded the result as $7 \cdot 6,8 \cdot 2,8 \cdot 4,9 \cdot 1,9 \cdot 8,10,10,10$, and 10 (total $83 \cdot 1$, median $9 \cdot 8$ ); the nine with horizontal scars graded the result as $3 \cdot 6,4 \cdot 3,4 \cdot 7,5 \cdot 1,5 \cdot 3,6 \cdot 5,6 \cdot 9,7 \cdot 1$, and 10 (total $53 \cdot 5$, median $5 \cdot 3$ ). The medians were significantly different ( $\mathrm{p}<0.01$, Wilcoxon double sided rank sum test)

The direction of Langer's lines at the lower umbilical verge was determined by two methods. Firstly, Langer's skin splitting experiment ${ }^{1}$ was recreated in 10 women, whereby a cone shaped trocar was used to pierce the skin at the lower 